\title{
RECONSTRUCTING DECONSTRUCTION IN ARCHITECTURE
}

\author{
IDHAM, Noor Cholis \\ Architecture Department, Universitas Islam Indonesia Yogyakarta \\ Email: noor.idham@uii.ac.id
}

\begin{abstract}
This paper examines deconstruction in architecture and forms used, which triggered by dispute of form and its scientification claimed by deconstructivists. Deconstruction terminologyis studied in the first part related to architecture field as a base knowledge. Some sample works of known deconstructionist architects are assessed in order to understand how their building is deconstructed and what forms they used. Discussion about form and its relation to other fields is then pursued by discussing the involvement of terminology of science, aesthetic pattern, and human life. The results of this discussion give clear understanding how form related to deconstruction in architecture are used.
\end{abstract}

Keywords: Deconstruction, form, fractal, architecture.

\section{INTRODUCTION}

It is not easy to follow the work of deconstructtionist architects. Since they used 'de-construction' terminology, which is came from other field in social science, everything then can be used as deconstructtion in architecture. Charles Jencks stated that the deconstruction in architecture is the answer of the challenge of modern science. As the architecture of the 'jumping universe' the work of deconstructionist is a proof that architecture is working in science (Jencks, 1997). However, many scholars steel hesitated with what Jencks argued. Salingaros loudly stated that the work of deconstructionists is just as 'anti-architecture' and nothing to do with the science (Salingaros et al., 2004). All deconstruction forms what Jencks lay claims to as scientific truth in architecture are wrong according to Salingaros. Based on this dispute in architecture, by going back to what is deconstruction and understanding how they used forms in their architecture, it will enlightening us to access what deconstructionist and anti-deconstructionist struggle for.

The term of deconstruction is originally used in linguistics, philosophy, and literary theory. It is the metaphysical assumptions involved in systematic attempts to basic knowledge of interconnected signs to renovate systems of relationships. It questions the fundamental conceptual of distinctions, or more clearly as oppositions, in Western philosophy through a close examination of the language and logic of philosophical and literary texts. This method found wide use from the early $20^{\text {th }}$ century. The techniques and ideas of deconstruction then have been used by scholars in history, sociology, educational theory, linguistics, art, and lately in architecture.
Deconstruction terminology was invented by Jacques Derrida (1930-2004), a French philosopher which was extending the philosophical excursion of Nietzsche (1844-1900) and Heidegger (1889-1976). Derrida postulated that all texts are based on hierarchical dualisms likes: male/female, being/non-being, reality/appearance, where the first element is considered as stronger and thus essentially true and that all systems of thought have an assumed center, or Archimedean point, upon which they are based (Deconstruction encyclopedia website). This term also refers to the way in which the 'accidental' features of a text can be seen as betraying or subverting, from its supposedly 'essential' message is delivered (Deconstructionist Theory website).

To 'deconstruct' an opposition is to explore the contradictions and tensions between the hierarchical ordering assumed in the text and other aspects of the text's meaning. The deconstruction 'displaces' the opposition by showing that neither term is most important; the opposition is a product, or 'construction,' of the text rather than something given independently of it.

\section{DECONSTRUCTION IN ARCHITECTURE}

The main connection between deconstructivist philosophy and architectural theory was through the philosopher Jacques Derrida's influence on Peter Eisenman. Peter Eisenman as well as Daniel Libeskind were putted their concern in the "metaphysics of presence," as a main subject of deconstructivist philosophy in architecture theory. The dialectic of presence and absence, or solid and void can be seen in much of Eisenman's projects. Both Derrida and Eisenman believe that the locus, or place of presence, 
is architecture, and the same dialectic of presence and absence is found in construction and deconstruction (Deconstructivism website). This can be assumed that architecture is also a language of communicating and meaning, so it can be treated by methods of linguistic philosophy.

Development of post-modern architecture that began in the late 1980's is actually the beginning of Deconstructivism in architecture since it stands in opposition to the ordered rationality of Modernism. However, its relationship with post-modernism is also absolutely opposite (Deconstructivism website). Deconstruction form or building is characterized by ideas of fragmentation and interest in manipulating ideas of a structure's surface or skin. It utilizes nonrectilinear shapes which serve to distort and dislocate some of the elements of architecture, such as structure and envelope. The finished visual appearance of buildings is characterized by an encouraging unpredictability and a controlled disorder.

A deconstructive architect is not one who pulls to pieces of buildings, but one who locates the essential dilemmas within buildings (http://www. elupton.com/index.php?id=11). The challenge in deconstructivism is to move architecture away from what its seen as the 'rules' of modernism such as "form follows function," "purity of form," and "truth to materials" (Deconstructivism website). For deconstructivists, the formal/classical/conventional geometry was the aspect to be denied, just like ornament was for post-modernists. Instead, the complication of geometry applied to the functional, structural, and spacial aspects of deconstruction buildings.

\section{THE WORKS OF DECONSTRUCTIONIST ARCHITECTS}

In order to understand the way deconstructionist work, here some works of well-known deconstructtivism architects, and the styles and forms they used.

\section{a. Frank Gehry}

Gehry works such as a house in California, Aerospace museum in Santa Monica, and restaurant in Kobe, mostly perform as sculptural expression rather than a place for certain function. Solid massive principle is used as a symbol of the presence of absence. In general, buildings left a sense of split composition, twisted, and unfinished (see figure 1).

\section{b. Peter Eisenman}

House I - X of Eisenman are organized as opposition for classical order. The spaces are formed as solid and void. However, the form itself does not opposite with the modern style in previous era. Cubism that he used still resembles the style of modern architecture in these houses (see figure 2).

\section{c. Rem Koolhaas}

Koolhaas's buildings such as apartment in Holland, Berlin, and Florida were based on typology combination. Abstract glassed facade interrupted by strange graphic pattern or form is his common style. Singapore tower project is the tower that not really loose from modern architecture where cubical tower box which used with certain movements. In case of

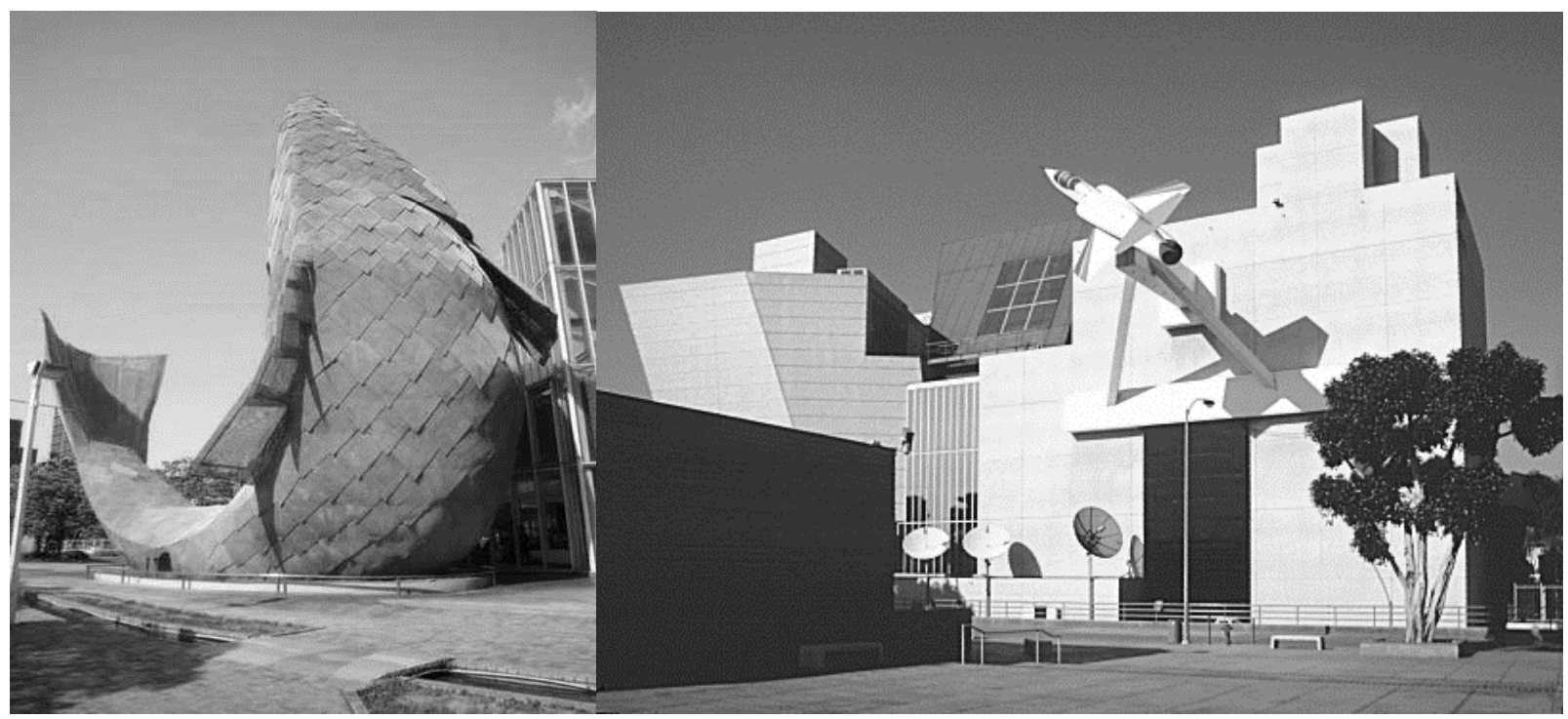

Figure 1. Kobe Restaurant (left), and Aerospace museum in Santa Monica (right). (source: www.listphile.com and www.bluffton.edu) 
Amsterdam building, the contrast form, circle and curved, which used for accent to the 'common style' of modern 'boxy' building (see figure 3).

\section{d. Zaha Hadid}

Philosophical concept as antithesis can be easily found in Hadid's buildings. The term of de-center, dissymmetry, misbalance, or de-function are widely used in her deconstruction concept. Much of her projects based on smooth curved form and façade. As deconstructionist, she putted form and function almost always not related. Form-analogy is more dominant such as wave (Cagliari project, since it is located in water front) and ball skin (Madrid project) (see figure 4).

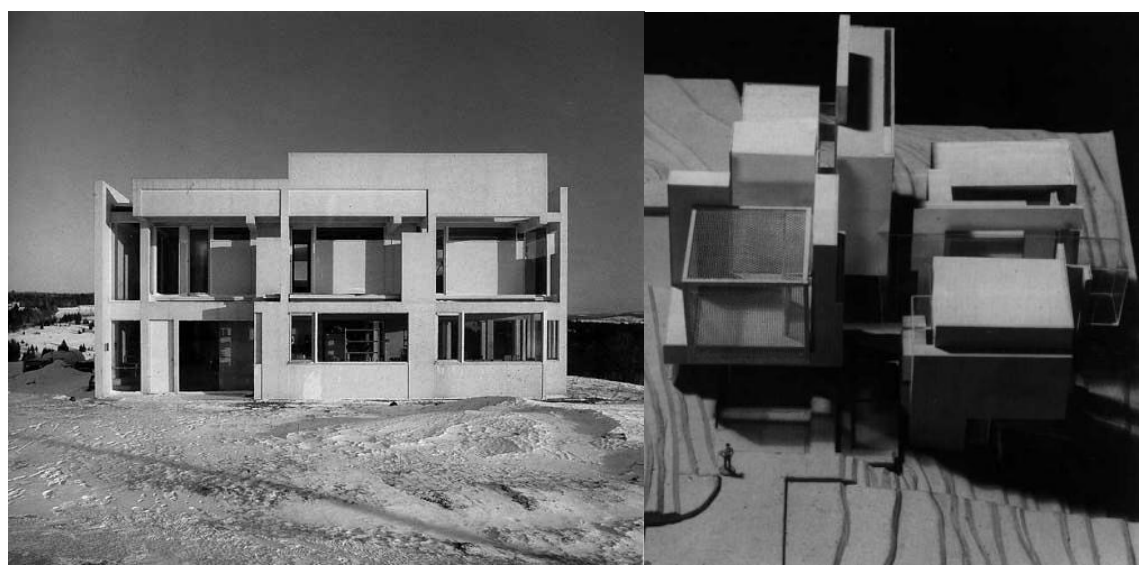

Figure 2. House I and X of Peter Eisenman (Source: www.arch1.uniroma1.it)

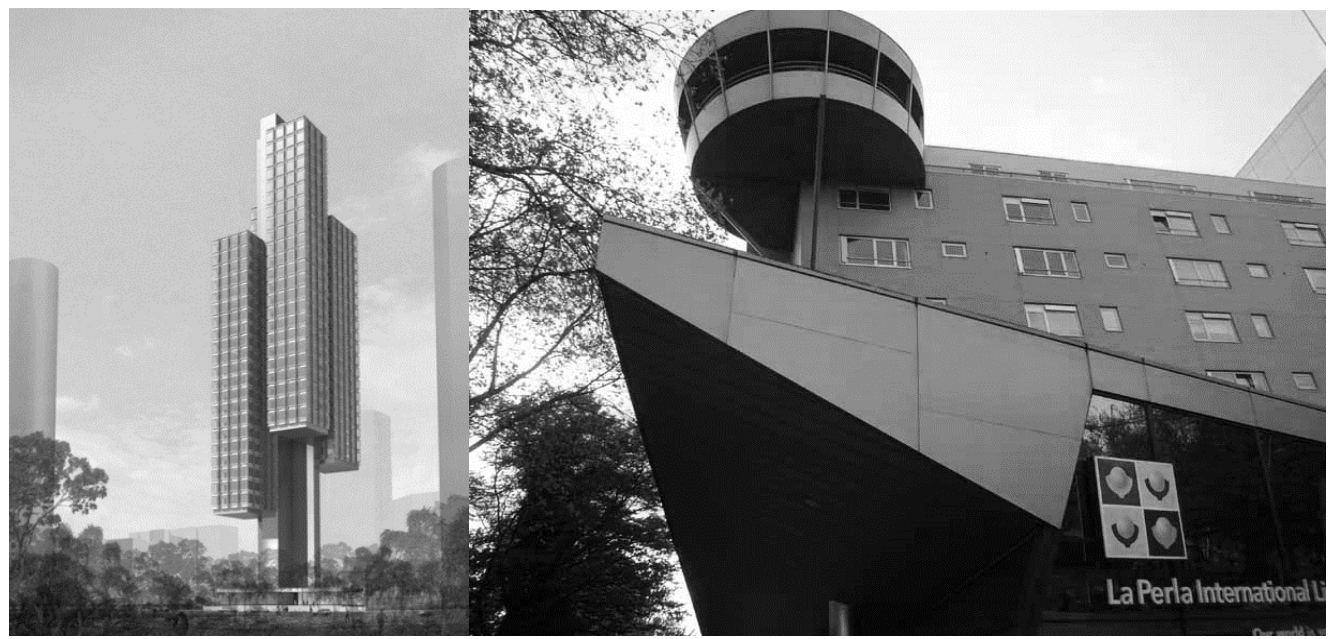

Figure 3. Koolhaas's Projects in Singapore (lift) and Amsterdam (right) (Source: www.building.co.uk and www.e-architech.co.uk)

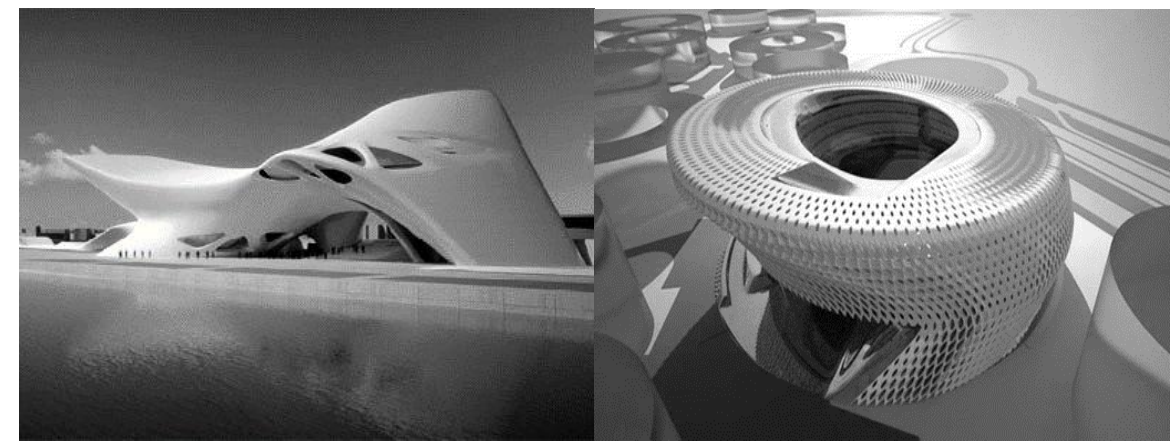

Figure 4. Zaha Hadid's Projects in Cagliari (left) and Madrid (right) (Source: www.floornature.com and www.architecturelist.com) 


\section{e. Bernard Tschumi}

From Parc La-Villette, Tschumi was using transgression theory based on human movement in order to create a form. He used deconstruction as process instead of as style. This is just a proof that the form that he used was still need a reason. At the works of Lindner Athletic Center and Blue Building, curved-asymmetry mass was used. The triangle columns of the Lindner has structural reason in order to make more rigid of building envelope system. However, the Blue Building appears to have not certain logic form for its un-straight vertical tower (see figure 5).

\section{f. Daniel Libeskind}

Libeskind's buildings were mostly designed by jugged style, sharp corner and loose orientation. Disregarding the type and function of the building, Jewish museum in Berlin and in Hongkong as well as WTC project, represents his similar style. Libskind is one of deconstructionist architect that really has 'true decon' in his style. Almost forms are appeared without any reasons (see figure 6).

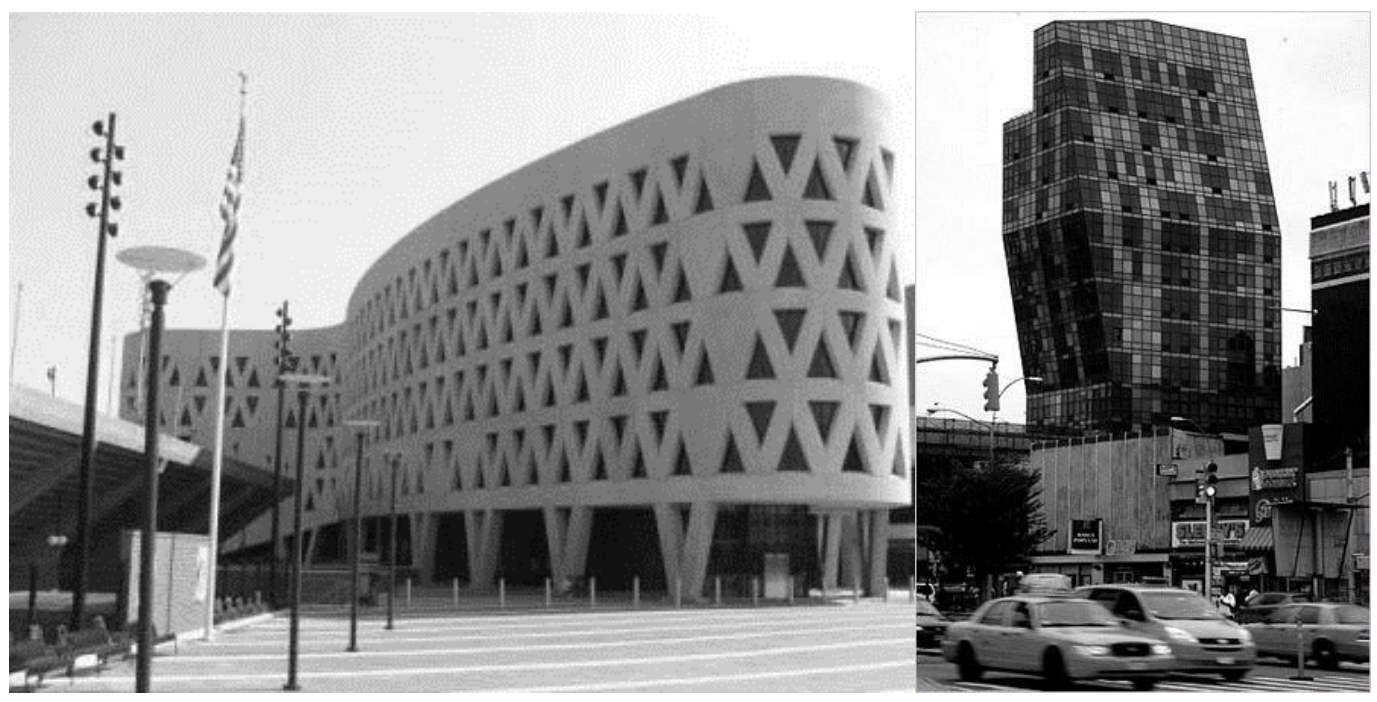

Figure 5. Bernard Tschumi's Lindner Athletic Center (left) and Blue Building (right)

(Source: www.floornature.com and www.artadox.com)

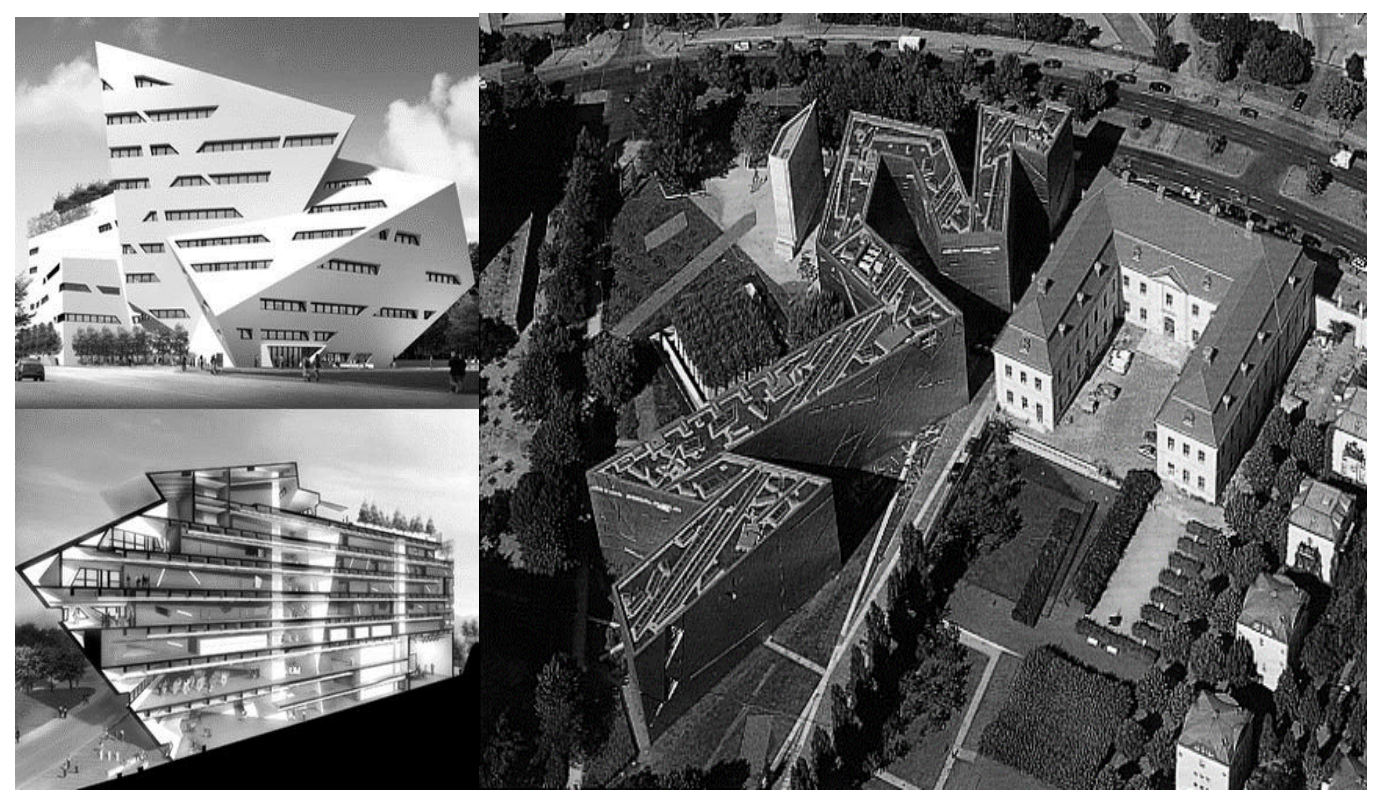

Figure 6. Libeskind's projects in Hongkong (left) and Jewish Museum in Berlin (right) (Source: from4.static.flickr.com and www.rockwool.dk) 


\section{FORM IN DECONSTRUCTION}

In design projects and in architectural texts of deconstructivist, as Jencks stated, proposed about 'fractals', 'emergence', 'self similarity', 'chaos', 'nonlinear system', and 'complexity' which are completely scientific terms (Jencks, 1997). All these terms are actually referring the forms in nature, and fractal can represents all these term since the meaning of all the terms is almost similar. According to Jencks, deconstruction forms were based in scientific terms as a proof that deconstruction as part of science. However, according Salingaros this was brought loosely disregarding the true meaning as science do but just to promote their projects and themselves (Salingaros et al., 2004).

Term of fractals, actually, was first discussed by Mandelbrot in 1978 but the idea was identified as early as 1925 . A fractal is an object or quantity that displays self-similarity on all scales. Fractals then have been investigated for their visual qualities as art, their relationship to explain natural processes, music, medicine, and in mathematics. Mathematical Fractals then represent the science and technology. The illustrations bellow explain how the fractal forms are formed by mathematical and graphical iteration (Ibrahim and Krawczyk, 2009) (see figure 7).

From the work of some well-known deconstructionist architects above, not all of them were using the form of fractal except Libeskind and Gehry. However, if the fractal is really used in architecture of deconstruction, the use of similar form in different scale should be considered. But if we examine the work of Gehry i.e. Bilbao museum, or the work of
Libeskind i.e. Jewish museum, the real fractal can not be found. Instead, they use un-similar forms in many scales.

The others such as Eisenman or Koolhaas works were even not use the form of fractal on all their buildings. So, the term of fractal alone cannot be used to represent the deconstruction form. Instead, according to some scholar, the work of deconstructtionist can be marked in general as:

a. Anti Synthesis

Deconstruction architecture is not result of systematic program. Intuition is preferable. 'Black box' were used before in traditional architecture is reemerged. Almost forms used are without reasons and logical thinking. However, architect cannot use his own intuition without any dealing in, since they are designing not only for themselves, but many aspects should also be considered.

\section{b. Anti Function}

Form and function do not have dependent relationship. In traditional architecture, forms are always have meaning; but in modern architecture, forms are connected to function. In Post-modern architecture such as deconstruction, there is even without any concept to be connected. However, space, as a result of the form should be related to the function itself. Otherwise, the result will not considered as real architecture but sculpture.

c. Anti Order

'Free will' manifested by free form is aim of the building and there is no any rule accessed. Deconstruction does not have certain order which will give limitation in form creation. Any attempt to systemize deconstruction is unacceptable.
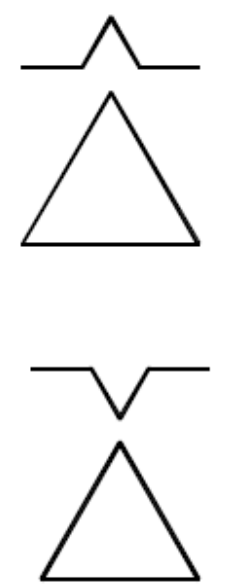

Generator and Initiator
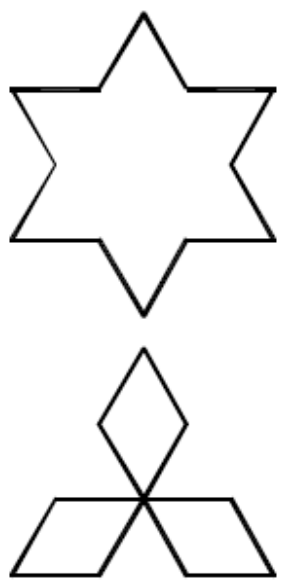

First iteration
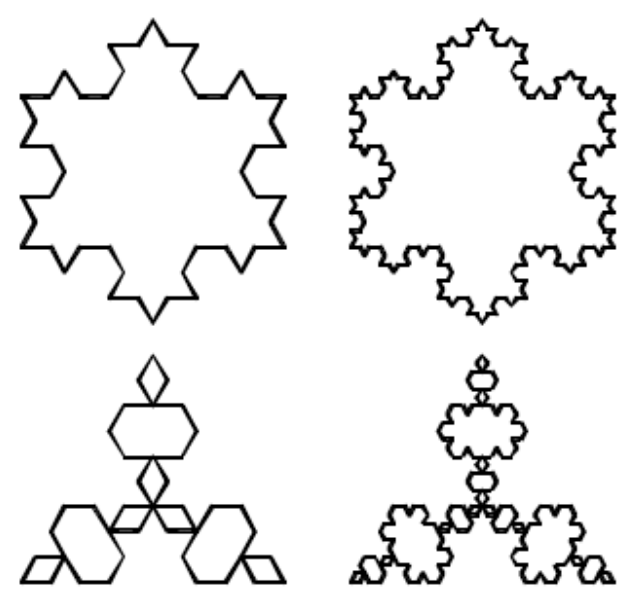

Second iteration

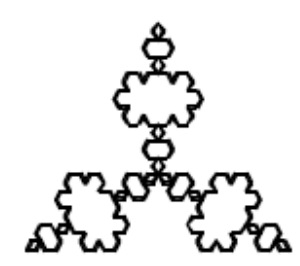

Third iteration

Figure 7. The Fractal generation from geometric shape (Source: Ibrahim and Krawczyk, 2009) 


\section{d. Logo centric}

Logo centric is a combination of architectural and philosophical concept. Architecture will be processed as metaphysical articulation in multivalent. This concept reflects the logo centric authority since order is not absolute. The main aim is to split the common order. "Me architecture" is the term used for this concept and context then is not the important issue anymore.

From characteristics above, deconstruction architecture is architecture without rule and order so considered as 'anti-architecture' (Salingaros et al, 2004). What Jencks tried to correlate the forms of deconstruction architecture as a rule of science is not match with these facts. Form scientification is just the matter of giving the order while the aim of deconstruction itself is for cutting the factual order, splashing 'anti-form' or rudely can be considered as dangerous virus to the environment.

\section{FORM AND REASON IN ARCHITECTURE}

In the case of deconstruction architecture, form that they used still has actually certain reasons how and why they used. Architect's mind is the most but not the only one. In case of using special materials, technology and construction are the reason. In case of dealing with the budget, cost then become first concern (e.g. Libeskind 'snake' Juwish museum originally had sloped facade, but because of the budget force, they made vertical instead). There is no certain form losing from reason in any style of architecture, even for what so-called deconstruction. Form is engendered in architecture by many reasons. Including the work of deconstructivist, there should be a certain reason. Form can be generated according to:

- Building type (typology, morphology, and planning type)

- Technology (engineering, building material, construction)

- Cost (economic, quantity survey, building management)

- Aesthetics (philosophy of arts)

- User and social preferences

- Architect's mind

Back to ancient time, number and geometry were used to determine the architectural form. It was broadly used in architecture theory to determine the abstract principles underlying architectural form which will enable architects to design good architecture. Since at least Greek times, it has seemed self-evident that the fundamental principles of architecture from must be mathematical (Stevens, (1990). In renaissance time, the beauty of building is the integration of the proportion of its parts into harmonious whole. And this harmony can be obtained in precisely the same way as musical harmony, through whole number ratios (see figure 8).

The Divine Proportion, the Golden Mean, Fibonacci series, or Phi number is mathematic terminology that was used to determine the form and composition. Many built environment and also the nature itself is believed have special order regarding to these mathematical terminology (Phinest). It is understood by this way, architecture is the science itself. The Nature of Order of Christopher Alexander's also profound arguments that order in both nature and in what we build are essentially the same (Salingaros). Scientific rule using a synthetic whose truth can be discovered only by investigation of the world. Its truth is dependent on the way that the world is. While analytic propositions, where mostly deconstruction argument from, are not about the world. The principle of contradictions in deconstructtion is to show that it does not care if what is true or not. Unfortunately, this is clearly not the attitude of science.
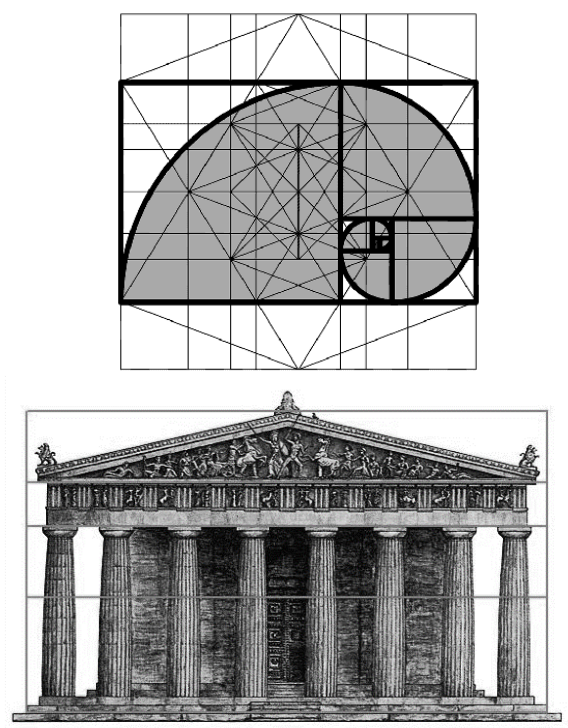

THE PARTHENON

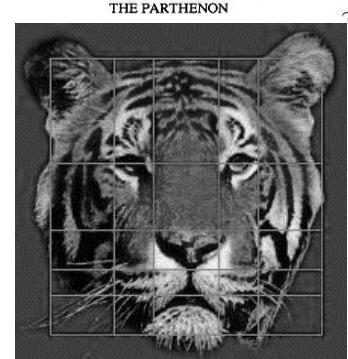

Figure 8. Divine Proportion can be traced both in built and natural forms (Source: www.phinest.com) 


\section{FORM: BETWEEN LIFE AND DEATH IN DECONSTRUCTION}

Deal with the form and its scientification, Jencks stated that the fractals which were used indeconstruction architecture were already developed in nature. Salingaros then countered that the term that they called fractals itself is faked. Deconstruction forms are stated with no any meaning and order which is correlated with the absence of life.

Deconstruction style appeared as the geometrical presence of 'death' in buildings such as:

- Not humanize. The building is built deliberately without a connective scaling hierarchy. Dehumanizing structures and spaces either too small or too large for a human being to relate to. Corners and sharp edges projecting toward people.

- Not naturalistic. Lacking connective symmetries and attachment to the gravitational axis. Shapes and forms stand out from nature.

- Not logic. Random, geometrically disconnected units that have no obvious means of support.

The quality of space is intended to sheer, empty surfaces without internal differentiations. It also physically shift our perceptual attention to their edge surfaces unresponsively or intentionally repulsive to our visual and tactile senses, and which can be colorless, smooth or rough, or made of sleek materials such a shiny metal and glass.

In opposite side, natural form then can be associated by the form of life which has properties [2]:

- has connectivity and pattern at its heart

- as "organized complexity", a potent mixture of rule and contingency, order and spontaneity

- not definable through traditional mathematical equations which purport to give "an answer", but is more of an unfolding, comparable to the action of a computer program

- a genetic algorithm that evolves and develops complexities as it learns

- not just complex, but even more mysteriously, perhaps it is ordered, displaying an incredible range of symmetries

Life seems always correlated with aesthetic as the logical truth of the nature. According to Alexander's 15 aesthetic properties, are: 1). Levels of scale, 2). Strong centers, 3). Boundaries, 4). Alternating repetition, 5). Positive space, 6). Good shape, 7). Local symmetries, 8). Deep interlock and ambiguity, 9). Contrast, 10). Gradients, 11). Roughness, 12). Echoes, 13). The void, 14). Simplicity and inner calm,
15). Non-separateness (Salingaros). All these items are also the properties of life itself which is opposite with the deconstructivism principles. It is very rarely that the principles above can be found in the forms of deconstruction architecture. Many building and space was developed by 'death' form rather than 'life' form. As resemble of the bad memories such as Holocaust Museum in Berlin or Jewish Museum is fine, but if the similar form also used for another function which rather reminding of the life, this architectural style only degrading the quality of architecture itself.

\section{CONCLUSION}

Form is the final product of architecture. By certain reasons, the form is generated. What Jencks claimed for deconstruction architecture directly related to modern science in its forms as fractal, emergence and so on is not truly right. Deconstruction architecture can use any form without any reason, or even the science itself. Anyhow, in fact, some forms are still need justification and all of them do not need to be forced as related to scientific terminology. In other hand, what Salingaros offense to deconstructionist style is also not completely acceptable. In architecture, scientification is not just the matter related openly to scientific term but also the process explainable or not. Even though not directly related to the term itself, form is still can be accepted as long as it has certain reason what how and why it related to the aim of architecture itself, rather than the aim of builder or architect. In any development, nature still provides the best example for human being. Exploring the form laid behind the nature is one of the proper ways to search the best answer for the architecture.

\section{REFERENCES}

Deconstruction encyclopedia, from http://encyclopedia2.thefreedictionary.com/deconstruction

Deconstructionist Theory, from http://prelectur. stanford.edu/lecturers/derrida/rorty.html

Deconstructivism, from http://en.wikipedia.org/wiki/ Deconstructivism

From http://www.elupton.com/index.php?id=11

Ibrahim and Krawczyk. (2009). Generating Fractals Based on Spatial Organizations, Illinois Institute of Technology, College of Architecture, Chicago, IL USA, from http://www.iit.edu/ kraw czyk/fract01.pdf

Jencks, C. (1997). The Architecture of the Jumping Universe, Academy Edition, London. ISBN: 1 854904868 
Phinest, from http://goldennumber.net/

Salingaros, et al. (2004). Anti-Architecture and Deconstruction, Umbau-Verlag, Solingen, Germany. ISBN 3-937954-01-5

Salingaros, Some Notes on Christopher Alexander from http://zeta.math.utsa.edu/ yxk833/Chris. text.html.

Stevens, Gary (1990). The Reasoning Architect: Mathematics and Science in Design, McGrawHill New York, ISBN 0-07-061391-5 